\title{
Prevalence and distribution of triticeal cartilage
}

\author{
E. Emre®, R.F. Akkoc(i), M. Ogeturk® \\ Department of Anatomy, Faculty of Medicine, Firat University, Elazig, Turkey \\ [Received: 10 September 2020; Accepted: 9 December 2020; Early publication date: 30 December 2020]
}

Background: The triticeal cartilage can be found in the lateral thyrohyoid ligament. The triticeal cartilage may exist in different shapes and locations, may be present unilaterally or bilaterally, or absent. The study aims to determine the prevalence, distribution, level, shape, and the degree of ossification of the triticeal cartilage by using three-dimensional computed tomography angiography (CTA).

Materials and methods: Computed tomography angiography images of 1450 patients (785 women and 665 men), obtained in the period from 1 January 2017 to 30 September 2019, were evaluated retrospectively. Any unilateral or bilateral presence or the absence of triticeal cartilage was recorded with its anatomical level, shape, and degree of ossification.

Results: At least one triticeal cartilage was found in the CTA images of 57.4\% (833 out of 1450) patients. The prevalence was 51.3\% in women (403 out of 785) and $64.7 \%$ in men (430 out of 665). Bilateral triticeal cartilages were more common compared to unilateral ones. Ossification was most commonly mild at a rate of $39.1 \%$. A round-shaped triticeal cartilage was the most common form at a rate of $46.6 \%$. Triticeal cartilage was detected at various intervertebral disc levels from the second and third cervical vertebrae to the level of the sixth cervical vertebra. Conclusions: Triticeal cartilage is common in the Turkish population and it should receive substantial attention from clinicians because it can be confused with calcified plaques and fractures of the superior horn of the thyroid cartilage. Therefore, for appropriate diagnoses and treatment, it is important to know the prevalence of triticeal cartilage with its distribution, intervertebral disc levels of location, shapes, and ossification degrees. (Folia Morphol 2022; 81, 1: 150-156)

Key words: triticeal cartilage, computed tomography angiography, thyrohyoid complex, triticeal ossification

\section{INTRODUCTION}

Triticeal cartilage (TC) is a type of cartilage that can be found in the lateral thyrohyoid ligament. TC may exist unilaterally or bilaterally or may be absent $[1,3,5,11]$. TC can be found at the level of the third and fourth cervical vertebrae which is in line with the carotid bifurcation, usually between the superior horn of the thyroid cartilage and the tip of the greater horn of the hyoid bone. TC is observed in the shape of wheat grain. The function of TC is yet to be established; however, some researchers suggest that TC strengthens the lateral thyrohyoid ligament [1, 3]. The theory of Wilson et al. [12] suggests that TC has no function in humans (Fig. 1).

Triticeal cartilage is composed of hyaline cartilage $[7,12]$. As other laryngeal cartilages, TC tends to ossify, too. An ossified TC may be mistaken for calcified plaques in the carotid artery in panoramic radiogra-

Address for correspondence: Dr. M. Ogeturk, Department of Anatomy, Faculty of Medicine, Firat University, Elazig, Turkey, e-mail: mgeturk@gmail.com

This article is available in open access under Creative Common Attribution-Non-Commercial-No Derivatives 4.0 International (CC BY-NC-ND 4.0) license, allowing to download articles and share them with others as long as they credit the authors and the publisher, but without permission to change them in any way or use them commercially. 

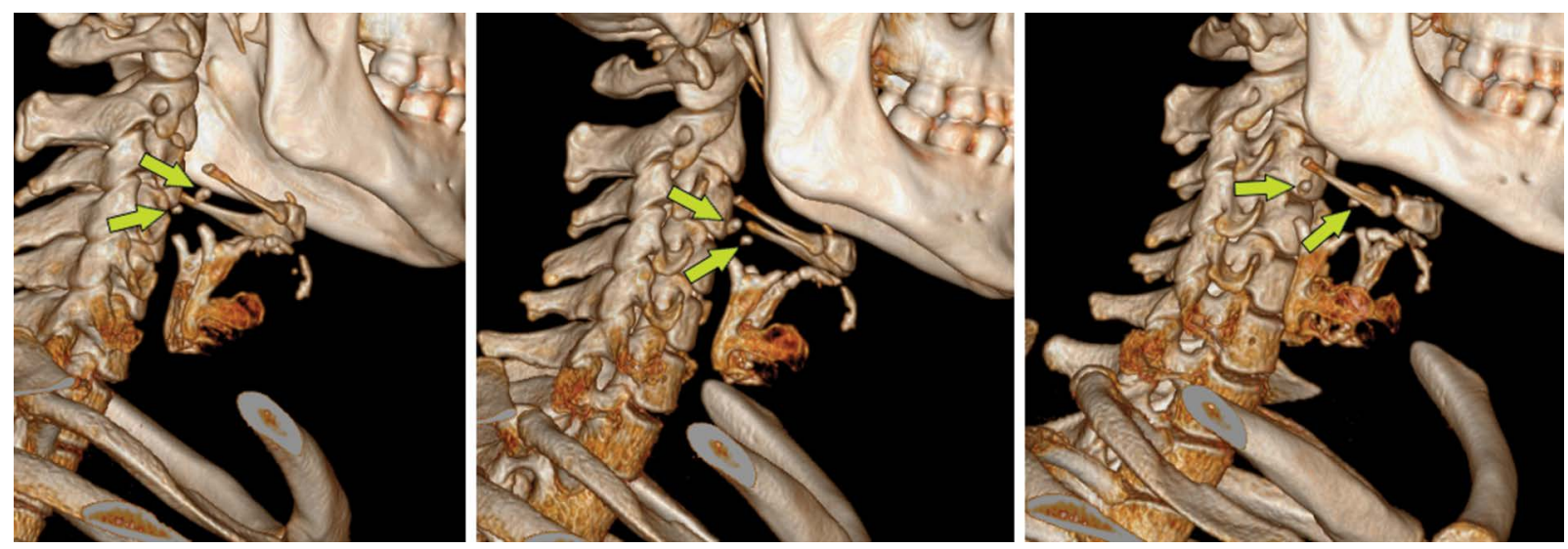

Figure 1. Three-dimensional reconstruction of computed tomographic angiography images. Yellow arrow demonstrates triticeous cartilage.

phy and computed tomography images, especially for calcified plaques at the carotid bifurcation level $[1,8,10]$. Furthermore, an ossified TC has been reported to be mistaken for the fractures of the superior horn of the thyroid cartilage [6]. An enlarged and ossified TC has been reported to cause dysphagia and odynophagia and to become symptomatic after endotracheal intubation [4]. Additionally, an enlarged TC has been reported to cause clinical symptoms similar to those of a foreign body [9].

To the best of our knowledge, there are no studies in the literature reporting the prevalence and distribution of TC by the level of location and gender. Therefore, the aim of this study has been to determine the frequency, distribution, location levels, shape, and the degree of ossification of TC and to reveal gender differences.

\section{MATERIALS AND METHODS}

Computed tomography angiography (CTA) images obtained in the period between 1 January 2017 and 30 September 2019 from 1643 individuals, who were 25 years old or older, were examined in the study. The CTA images of individuals who had pathological structures in the neck area and who underwent surgical interventions of the larynx or the CTA images with poor image quality were not included in the evaluation. The present study included 785 women and 665 men, making up 1450 individuals in total. The CTA images of these individuals were retrospectively evaluated. The age range of the individuals whose CTA images were evaluated was from 25 to 97 (mean \pm \pm standard deviation [SD] $63 \pm 14$ ) years.

The analyses of the CTA images, the degree of ossification, and the distribution of the shapes of TC were determined based on the study of Alqahtani et al. [3].

The calcification extent of TC was determined according to the study of Alqahtani et al. [3] and by comparing the calcification of TC to the density of the surrounding bone tissues in the CTA images. The calcification extent of TC was consulted by an experienced radiology specialist. Additionally, utilising the software used during the evaluation of angiography images, the exposure degrees of the images were adjusted. Thus, each image was evaluated using equivalent exposures.

In the CTA images, the unilateral or bilateral presence or the absence of TC, and the intervertebral disc levels of TC location were evaluated. The evaluations were performed independently by two researchers. Then, the data were compared accordingly. When an agreement could not be made, a third researcher evaluated the images again independently. The data were accepted valid when two researchers reached an agreement.

\section{Statistical analysis}

The statistical analyses were performed with the SPSS statistical package, version 22.0 (SPSS Inc., Chicago, IL, USA). The categorical values were summarised as numbers and percentages. The $\chi^{2}$ test was used for comparing the categorical data between the groups. The level of statistical significance in all tests was accepted as $p<0.05$.

\section{RESULTS}

The presence of at least one TC was found at rates of $51.3 \%$ in women (403 in 785 ), $64.7 \%$ in men (430 in 665 ), and $57.4 \%$ in the total study population (833 
Table 1. Incidence of triticeal cartilage

\begin{tabular}{lccc}
\hline Cartilago triticea & Women & Men & All subjects \\
\hline None & $382(48.6 \%)$ & $235(35.3 \%)$ & $617(42.6)$ \\
Unilateral: & & & \\
$\quad$ Right & $65(8.3 \%)$ & $53(8)$ & $118(8.1)$ \\
$\quad$ Left & $87(11.1 \%)$ & $68(10.2)$ & $155(10.7)$ \\
Bilateral & $251(32 \%)$ & $309(46.5 \%)$ & $560(38.6)$ \\
Total & $785(100 \%)$ & $665(100 \%)$ & $1450(100 \%)$ \\
\hline
\end{tabular}

in 1450). The incidence of TC in the overall study population and by gender has been presented in Table 1 . Presence of TC in individual decades of life, broken down by gender, has been presented in Table 2 . There was not statistically significant difference between the age groups and the incidence of TC in women, men, and regardless of gender.

Examination of the degree of ossification of TC revealed mild ossification in $39.1 \%$ of the study population and it was found out to be the most commonly seen ossification type. The least common type of ossification was the apparent ossification at a rate of $15.5 \%$. The ossification degrees in the overall study population and distribution by gender have been presented in Table 3. While there was not a statistically significant relationship between the age groups and the degree of ossification ( $p>0.05)$, a significant relationship was found between the ossification degrees and gender $(p<0.05)$. TC in women was more intensely ossified compared to men (Table 3). The degrees of ossification of TC have been shown in Figure 2.

A rounded TC was the most common form at a ratio of $40.6 \%$ and a spindle-shaped TC was the rarest form at a rate of $2.2 \%$ (Table 4 ). The shapes of TC observed in the sagittal CTA images have been shown in Figure 3.

The fourth cervical vertebra was the most common level of TC location at a rate of $42.1 \%$ and the least common location level was the sixth cervical vertebra at a rate of $0.2 \%$ (Table 5 ). In the lateral thyrohyoid ligament, TC was detected at different intervertebral disc levels (Fig. 4).

\section{DISCUSSION}

Knowing the presence, structure (ossified or cartilage structure), and location levels of TC may be important for making a differential diagnosis across calcified arterial plaques, fractures of the superior horn of thyroid cartilage, and calcified soft tissue abnormalities. We think that such information will provide beneficial tools to clinicians when they examine the radiological images of the neck region. In the present study, the CTA images of the eligible individuals were retrospectively reviewed for the incidence, distribution, shapes, the intervertebral disc levels of location, and ossification degrees of TC. As a differentiation point, this study has been conducted on the CTA images from 1450 individuals, which is the largest population ever reported by similar studies in the literature.

Studies report the incidence of TC in the range from $13.5 \%$ to $68.1 \%$ as found in cadavers, autopsy cases, and CTA images from various populations $[2,3,8,11,12]$. The results of the present study are within this range and close to the upper limit. The studies reporting the incidence of ossification of TC on panoramic radiographs $[1,5]$ were not included in the evaluation because they neither reflected the prevalence of ossified TC nor the precise prevalence.

Table 2. Incidence of triticeal cartilage (TC) in age groups

\begin{tabular}{|c|c|c|c|c|c|c|}
\hline \multirow[t]{2}{*}{ Age groups [years] } & \multicolumn{2}{|r|}{ Women } & \multicolumn{2}{|r|}{ Men } & \multicolumn{2}{|c|}{ All subjects } \\
\hline & $\mathbf{N}$ & Subjects with TC (\%) & $\mathbf{N}$ & Subjects with TC (\%) & $\mathbf{N}$ & Subjects with TC (\%) \\
\hline $25-34$ & 31 & $16(51.6 \%)$ & 17 & $8(47.1 \%)$ & 48 & $24(50 \%)$ \\
\hline $35-44$ & 78 & $39(50 \%)$ & 48 & $34(70.8 \%)$ & 126 & $73(57.9 \%)$ \\
\hline $45-54$ & 149 & 77 (51.77\%) & 91 & $55(60.4 \%)$ & 240 & $132(55 \%)$ \\
\hline $55-64$ & 198 & $103(52 \%)$ & 158 & $108(68.4 \%)$ & 356 & $211(59.3 \%)$ \\
\hline $65-74$ & 190 & $100(52.6 \%)$ & 203 & $132(65 \%)$ & 393 & $232(59 \%)$ \\
\hline $75-84$ & 121 & $60(49.6 \%)$ & 122 & $74(60.7 \%)$ & 243 & $134(55.1 \%)$ \\
\hline$\geq 85$ & 18 & $8(44.4 \%)$ & 26 & $19(73.1 \%)$ & 44 & $27(61.4 \%)$ \\
\hline$P$ & & $P=0.994$ & & $P=0.377$ & & $P=0.760$ \\
\hline
\end{tabular}


Table 3. Ossification degrees of triticeal cartilage

\begin{tabular}{|c|c|c|c|c|c|}
\hline & \multicolumn{5}{|c|}{ Ossification degrees } \\
\hline & Cartilago triticea & $\begin{array}{l}\text { Mild triticeal } \\
\text { ossification }\end{array}$ & $\begin{array}{l}\text { Moderate triticeal } \\
\text { ossification }\end{array}$ & $\begin{array}{l}\text { Apparent triticeal } \\
\text { ossification }\end{array}$ & Total \\
\hline \multicolumn{6}{|l|}{ Women: } \\
\hline Right & $57(18 \%)$ & $88(27.9 \%)$ & $100(31.6 \%)$ & $71(22.5 \%)$ & $316(100 \%)$ \\
\hline Left & $45(13.3 \%)$ & $121(35.8 \%)$ & $91(26.9 \%)$ & $81(24 \%)$ & $338(100 \%)$ \\
\hline Total & $102(15.6 \%)$ & $209(32 \%)$ & $191(29.2 \%)$ & $152(23.2 \%)$ & $654(100 \%)$ \\
\hline \multicolumn{6}{|l|}{ Men: } \\
\hline Right & $107(29.6 \%)$ & $167(46.1 \%)$ & $54(14.9 \%)$ & $34(9.4 \%)$ & $362(100 \%)$ \\
\hline Left & $117(31 \%)$ & $169(44.8 \%)$ & $61(16.2 \%)$ & $30(8 \%)$ & $377(100 \%)$ \\
\hline Total & $224(30.3 \%)$ & $336(45.5 \%)$ & $115(15.6 \%)$ & $64(8.6 \%)$ & $739(100 \%)$ \\
\hline \multicolumn{6}{|c|}{ All subjects: } \\
\hline Right & $164(24.2 \%)$ & $255(37.6 \%)$ & $154(22.7 \%)$ & $105(15.5 \%)$ & $678(100 \%)$ \\
\hline Left & $162(22.8 \%)$ & $290(40.5 \%)$ & $152(21.2 \%)$ & $111(15.5 \%)$ & $715(100 \%)$ \\
\hline Total & $326(23.4 \%)$ & $545(39.1 \%)$ & $306(22 \%)$ & $216(15.5 \%)$ & $1393(100 \%)$ \\
\hline
\end{tabular}
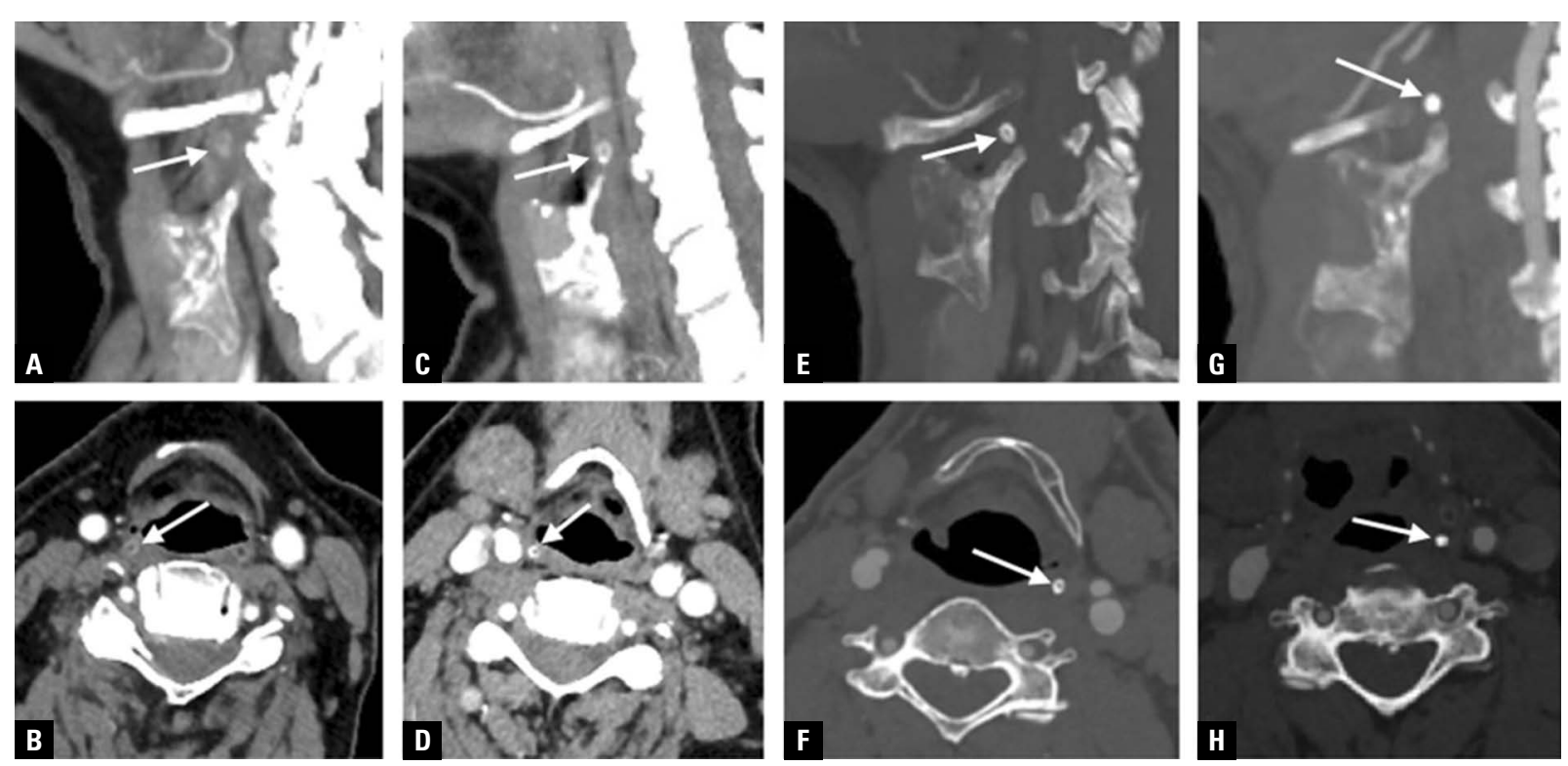

Figure 2. Sagittal $(\mathbf{A}, \mathbf{C}, \mathbf{E}, \mathbf{G})$ and axial $(\mathbf{B}, \mathbf{D}, \mathbf{F}, \mathbf{H})$ planes showing a variety of ossification intensities in cartilago triticea in the computed tomography angiography images. Arrows demonstrates cartilago triticea (A, B), mild triticeal ossification (C, D), moderate triticeal ossification (E, F), apparent triticeal ossification $(\mathbf{G}, \mathbf{H})$.

The incidence of having bilateral TC was reported to be higher than having a unilateral one in many studies investigating the incidence and distribution $[3,5,6,8,11]$. This finding is consistent with the results of the present study. On the other hand, Wilson et al. [12] reported in their study on cadavers that the incidence of unilateral TC was higher than the incidence of bilateral TC.

Our findings, suggesting that the prevalence of TC is significantly higher in men than in women, support the results reported by previous studies $[3,6,11]$. However, Wilson et al. [12] reported that the prevalence of TC was not significantly different between the genders.

As reported in previous studies, no correlations were found between the degrees of ossification of TC and the age $[3,11]$. In this study, a 28-year-old man was observed having a markedly ossified TC, whereas a 91-year-old woman was found to have an unossified bilateral TC. 
Table 4. Distribution of triticeal cartilage by shape

\begin{tabular}{|c|c|c|c|c|c|c|c|c|}
\hline & \multicolumn{8}{|c|}{ Shape } \\
\hline & Round & Oval & Spindle & Elongated & Rectangular & Teardrop & Triangular & Total \\
\hline \multicolumn{9}{|l|}{ Women: } \\
\hline Right & 165 (52.2\%) & $108(34.2 \%)$ & $8(2.5 \%)$ & 7 (2.2\%) & $4(1.3 \%)$ & $19(6 \%)$ & $5(1.6 \%)$ & $316(100 \%)$ \\
\hline Left & 166 (49.1\%) & $115(34 \%)$ & 13 (3.8\%) & $9(2.7 \%)$ & $8(2.4 \%)$ & $19(5.6 \%)$ & $8(2.4 \%)$ & $338(100 \%)$ \\
\hline Total & 331 (50.6\%) & $223(34.1 \%)$ & $21(3.2 \%)$ & $16(2.4 \%)$ & 12 (1.9\%) & 38 (5.8\%) & $13(2 \%)$ & 654 (100\%) \\
\hline \multicolumn{9}{|l|}{ Men: } \\
\hline Right & $113(31.2 \%)$ & $153(42.3 \%)$ & $5(1.3 \%)$ & $39(10.8 \%)$ & 13 (3.6\%) & $14(3.9 \%)$ & 25 (6.9\%) & $362(100 \%)$ \\
\hline Left & $121(32.1 \%)$ & $134(35.5 \%)$ & $5(1.3 \%)$ & $43(11.4 \%)$ & 12 (3.2\%) & $42(11.2 \%)$ & 20 (5.3\%) & $377(100 \%)$ \\
\hline Total & 234 (31.7\%) & $287(38.8 \%)$ & $10(1.3 \%)$ & $82(11.1 \%)$ & 25 (3.4\%) & $56(7.6 \%)$ & $45(6.1 \%)$ & 739 (100\%) \\
\hline \multicolumn{9}{|c|}{ All subjects: } \\
\hline Right & 278 (41.0\%) & $261(38.5 \%)$ & $13(1.9 \%)$ & 46 (6.8\%) & $17(2.5 \%)$ & $33(4.9 \%)$ & $30(4.4 \%)$ & $678(100 \%)$ \\
\hline Left & 287 (40.2\%) & $249(34.8 \%)$ & $18(2.5 \%)$ & 52 (7.3\%) & $20(2.8 \%)$ & $61(8.5 \%)$ & $28(3.9 \%)$ & 715 (100\%) \\
\hline Total & $565(40.6 \%)$ & $510(36.6 \%)$ & $31(2.2 \%)$ & $98(7 \%)$ & $37(2.7 \%)$ & $94(6.7 \%)$ & $58(4.2 \%)$ & $1393(100 \%)$ \\
\hline
\end{tabular}

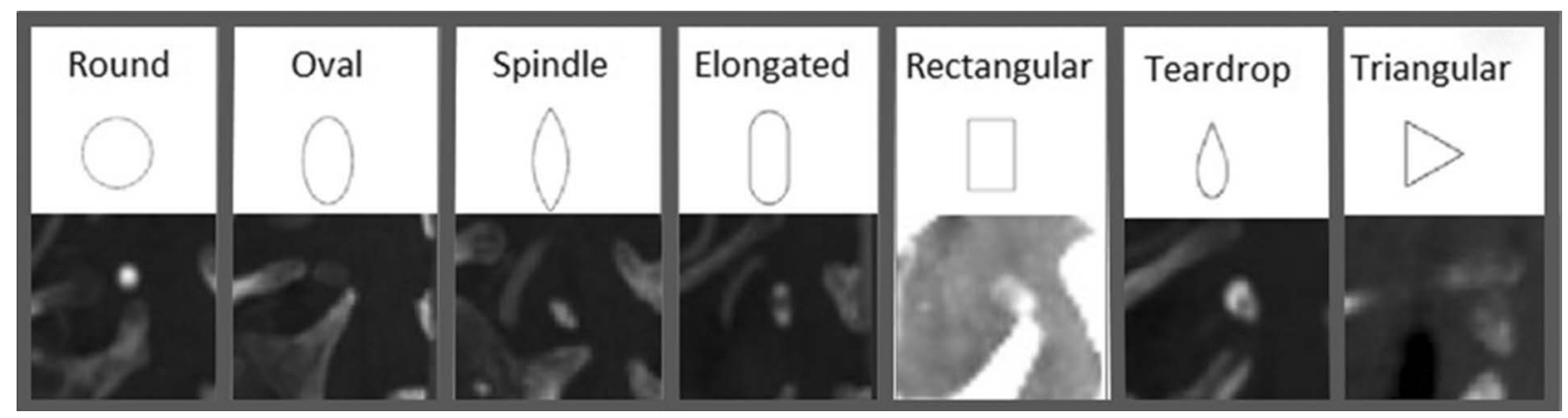

Figure 3. Various shapes of cartilago triticea in sagittal computed tomography angiography images.

Table 5. Triticeal cartilage's distribution by the level of location

\begin{tabular}{|c|c|c|c|c|c|c|c|c|c|}
\hline & \multicolumn{9}{|c|}{ Level } \\
\hline & C 2-3 & C 3 & C 3-4 & C 4 & C 4-5 & C 5 & C 5-6 & C 6 & Total \\
\hline \multicolumn{10}{|l|}{ Women: } \\
\hline Right & $3(0.9 \%)$ & $65(20.6 \%)$ & 71 (22.5\%) & $134(42.4 \%)$ & $34(10.8 \%)$ & $9(2.8 \%)$ & - & - & $316(100 \%)$ \\
\hline Left & $5(1.5 \%)$ & $70(20.7 \%)$ & $83(24.6 \%)$ & $134(39.6 \%)$ & $35(10.4 \%)$ & 11 (3.2\%) & - & - & $338(100 \%)$ \\
\hline Total & $8(1.2 \%)$ & $135(20.6 \%)$ & $154(23.5 \%)$ & $268(41 \%)$ & $69(10.6 \%)$ & $20(3.1 \%)$ & - & - & $654(100 \%)$ \\
\hline \multicolumn{10}{|l|}{ Men: } \\
\hline Right & - & $31(8.6 \%)$ & $83(22.9 \%)$ & $154(42.6 \%)$ & $68(18.8 \%)$ & $20(5.5 \%)$ & $3(0.8 \%)$ & $3(0.8 \%)$ & $362(100 \%)$ \\
\hline Left & $2(0.5 \%)$ & $33(8.7 \%)$ & $93(24.7 \%)$ & 165 (43.8\%) & 61 (16.2\%) & $21(5.6 \%)$ & $2(0.5 \%)$ & - & $377(100 \%)$ \\
\hline Total & $2(0.3 \%)$ & $64(8.7 \%)$ & $176(23.8 \%)$ & $319(43.2 \%)$ & $129(17.4 \%)$ & 41 (5.5\%) & $5(0.7 \%)$ & $3(0.4 \%)$ & $739(100 \%)$ \\
\hline \multicolumn{10}{|c|}{ All subjects: } \\
\hline Right & $3(0.4 \%)$ & $96(14.2 \%)$ & $154(22.7 \%)$ & $288(42.5 \%)$ & $102(15.1 \%)$ & $29(4.3 \%)$ & $3(0.4 \%)$ & $3(0.4 \%)$ & $678(100 \%)$ \\
\hline Left & $7(1 \%)$ & $103(14.4 \%)$ & $176(24.6 \%)$ & $299(41.8 \%)$ & $96(13.4 \%)$ & $32(4.5 \%)$ & $2(0.3 \%)$ & - & $715(100 \%)$ \\
\hline Total & $10(0.7 \%)$ & 199 (14.3\%) & $330(23.7 \%)$ & 587 (42.1\%) & 198 (14.2\%) & $61(4.4 \%)$ & $5(0.4 \%)$ & $3(0.2 \%)$ & $1393(100 \%)$ \\
\hline
\end{tabular}



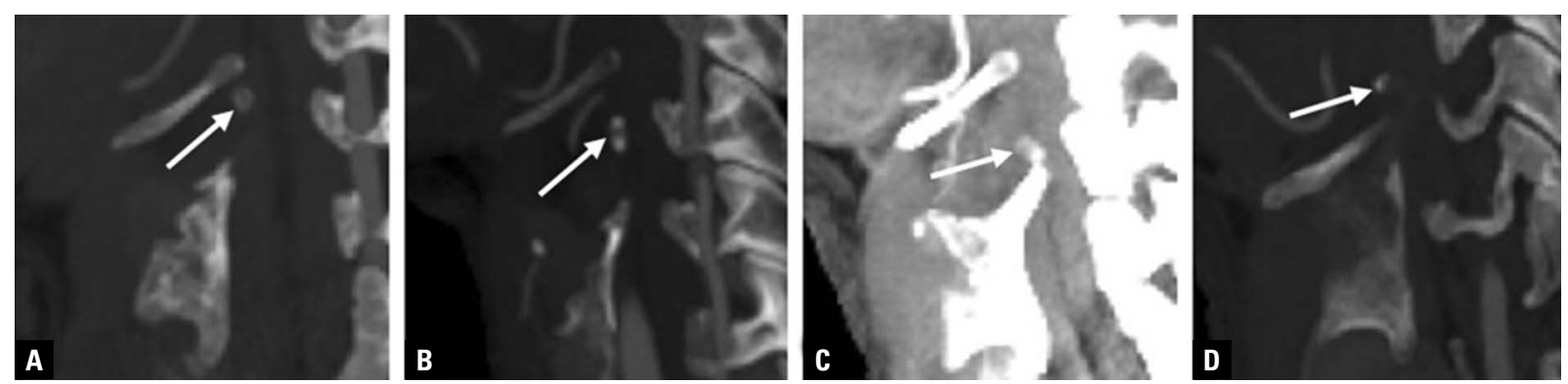

Figure 4. Arrows demonstrates the triticeal cartilage is seen in the upper (A), middle (B) and lower (C) positions as well as being observed at atypical sites (e.g. above cornu majus; $\mathbf{D}$ ) in the lateral thyrohyoid ligament.

A study on CTA images conducted by Alqahtani et al. [3] reported that mild ossification of TC was the most common form of ossification, while the least common form of ossification was apparent ossification. Alqahtani et al. [3] reported that they determined less intense degrees of ossification in men and more pronounced ossification in women. This result is consistent with the findings of our study. However, another study on CTA images conducted by Vatansever et al. [11] from our country found that mild ossification of TC was the least common and that the apparent ossification was the most common. Furthermore, Vatansever et al. [11] reported that there was not a relationship between ossification and gender.

Alqahtani et al. [3] evaluated shapes of TC in CTA images and reported that TC was found in various shapes including round, oval, spindle, elongated, rectangular, teardrop, and triangular forms. The study conducted by Vatansever et al. [11] reported that the oval shape of TC was the most common at a rate of $42.5 \%$ and the teardrop shape was the least common at a rate of $2.8 \%$. In the present study, the oval-shaped TC was the most common form after the round shape at a rate of $36.6 \%$. The teardrop shape of TC was determined as the least common form at a rate of $6.7 \%$ after the spindle and triangular-shaped ones.

Triticeal cartilage is not found on the same axis and plane even in people with bilateral TC. It may be located in different places within the thyrohyoid ligament. Moreover, TC has been reported to be observed at higher levels than the location of the greater horn of the hyoid bone in some people [3]. Such findings are consistent with our results. Furthermore, there are several reports stating that TC is usually located at the level of the third or fourth cervical vertebrae $[1,3,12]$. Similar to such reports, in our study, $80.1 \%$ of TC was found at the level of the third and fourth cervical vertebrae. To the best of our knowledge, no prevalence studies about the intervertebral disc level location of TC have been conducted and reported in the literature. This is the first study, reporting the prevalence and distribution of TC according to the level of location by gender and in the total population regardless of gender (Table 5).

The prevalence and morphology of TC vary from one population to another $[2,3,8,11,12]$. Although this study was conducted in a large population, it is limited to the geographical structure of the population and some ethnic features might have been reflected in the prevalence rates. Indeed, some differences are observed between the results of the present study and the first study from Turkey. We believe that these differences might have occurred because the present study included CTA images of individuals from overall Turkey, whereas, the first study in the literature evaluated CTA images of individuals from only one geographical region of Turkey [11].

\section{CONCLUSIONS}

When CTA and panoramic radiographic images are examined, clinicians should always note that TC can be mistaken for calcified plaques in the carotid artery and the fractures of the superior horn of the thyroid cartilage. Furthermore, care should be exercised in identifying this anatomical structure because the presence of an enlarged and ossified TC is associated with dysphagia, odynophagia, and clinical symptoms of foreign bodies in the respective location. Establishing the prevalence, distribution, intervertebral disc levels of location, various possible shapes, and ossification degrees of TC is critical to make an accurate diagnosis and conduct a proper treatment.

Conflict of interest: None declared 


\section{REFERENCES}

1. Ahmad M, Madden R, Perez L. Triticeous cartilage: prevalence on panoramic radiographs and diagnostic criteria. Oral Surg Oral Med Oral Pathol Oral Radiol Endod. 2005; 99(2): 225-230, doi: 10.1016/j.tripleo.2004.06.069, indexed in Pubmed: 15660097.

2. Ajmani ML. A metrical study of the laryngeal skeleton in adult Nigerians. J Anat. 1990; 171: 187-191, indexed in Pubmed: 2081705.

3. Alqahtani E, Marrero DE, Champion WL, et al. Triticeous cartilage CT imaging characteristics, prevalence, extent, and distribution of ossification. Otolaryngol Head Neck Surg. 2016; 154(1): 131-137, doi: 10.1177/0194599815615350, indexed in Pubmed: 26556461.

4. Alsarraf R, Mathison S, Futran N. Symptomatic presentation of an enlarged, ossified triticeal cartilage. Am J Otolaryngol. 1998; 19(5): 339-341, doi: 10.1016/s01960709(98)90010-2, indexed in Pubmed: 9758185.

5. Aoun G, Nasseh I. Calcified triticeous cartilage detected on digital panoramic radiographs in a sample of lebanese population. J Clin Imaging Sci. 2018; 8: 16, doi: 10.4103/ jcis.JCIS_11_18, indexed in Pubmed: 29770264.
6. Di Nunno N, Lombardo S, Costantinides F, et al. Anomalies and alterations of the hyoid-larynx complex in forensic radiographic studies. Am J Forensic Med Pathol. 2004; 25(1): 14-19, doi: 10.1097/01.paf.0000113931.49721. e4, indexed in Pubmed: 15075682.

7. Flynn W, Vickerton P. Anatomy, head and neck, larynx cartilage. StatPearls Publishing, Treasure Island (FL) 2020.

8. Joshi MM, Joshi SD, Joshi SS. Prevalence and variations of cartilago triticea. Int J Anat Res. 2014; 2: 474-477.

9. Mesa MM, Villarreal SM. Symptomatic presentation of calcified triticeal cartilage. Acta Otorrinolaringol Esp. 2009; 60(1): 75-76, doi: 10.1016/s2173-5735(09)70104-8.

10. Tamura $T$, Inui $M$, Nakase $M$, et al. Clinicostatistical study of carotid calcification on panoramic radiographs. Oral Dis. 2005; 11(5): 314-317, doi: 10.1111/j.16010825.2005.01125.x, indexed in Pubmed: 16120119.

11. Vatansever $A$, Demiryürek $D$, Tatar $I$, et al. The triticeous cartilage - redefining of morphology, prevalence and function. Folia Morphol. 2018; 77(4): 758-763, doi: 10.5603/FM.a2018.0034, indexed in Pubmed: 29611161.

12. Wilson I, Stevens J, Gnananandan J, et al. Triticeal cartilage: the forgotten cartilage. Surg Radiol Anat. 2017; 39(10): 1135-1141, doi: 10.1007/s00276-017-1841-z, indexed in Pubmed: 28314939. 